\title{
Spatial memory deficits in a mouse model of late-onset Alzheimer's disease are caused by zinc supplementation and correlate with amyloid-beta levels
}

\author{
Jane M. Flinn ${ }^{1}{ }^{*}$, P. Lorenzo Bozzelli ${ }^{1}$, Paul A. Adlard ${ }^{2}$ and Angela M. Railey ${ }^{1}$ \\ 1 Department of Psychology, George Mason University, Fairfax, VA, USA \\ ${ }^{2}$ Synaptic Neurobiology Laboratory, The Florey Institute of Neuroscience and Mental Health, The University of Melbourne, Parkville, VIC, Australia
}

\section{Edited by:}

Rodrigo Orlando Kuljiš, Zdrav Mozak

Limitada, Chile

\section{Reviewed by:}

Jacques Micheau, University of

Bordeaux 1, France

Luc Buee, INSERM, France

José M. Delgado-García, University

Pablo de Olavide, Spain

\section{*Correspondence:}

Jane M. Flinn, Department of

Psychology, George Mason

University, 4400 University Drive,

MSN 3F5, Fairfax, VA 22030, USA

e-mail: jflinn@gmu.edu
Much of the research in Alzheimer's disease (AD) that uses mouse models focuses on the early-onset form of the disease, which accounts for less than $5 \%$ of cases. In contrast, this study used a late-onset $A D$ model to examine the interaction between increased dietary zinc $(Z n)$ and the apolipoprotein $E(A p o E)$ gene. ApoE $\varepsilon 4$ is overrepresented in late-onset $A D$ and enhances $Z n$ binding to amyloid- $\beta(A \beta)$. This study sought to determine if elevated dietary Zn would impair spatial memory in CRND8 mice (CRND8), as well as mice who carry both the mutated human amyloid precursor protein (APP) and ApoE $\varepsilon 4$ genes (CRND8/E4). Mice were provided with either lab tap water or water enhanced with $10 \mathrm{ppm} \mathrm{Zn}\left(\mathrm{ZnCO}_{3}\right)$ for 4 months. At 6 months of age, spatial memory was measured by the Barnes maze. CRND8 mice exhibited significant memory deficits compared to WT mice, as shown by an increased latency to reach the escape box. For the CRND8/E4, but not the CRND8 mice, those given $\mathrm{Zn}$ water made significantly more errors than those on lab water. During the probe trial for the WT group, those on Zn water spent significantly less time in the target quadrant than those on lab water. These data suggest that increased dietary Zn can significantly impair spatial memory in CRND8/E4. WT mice given $\mathrm{Zn}$ water were also impaired on the 24-h probe trial when compared to lab water WTs. Within the CRND8/E4 group only, levels of soluble $A \beta$ were significantly correlated with average primary latencies. Within the Zn-treated CRND8/E4 group, there was a significant correlation between insoluble $A \beta$ and average primary errors. Levels of the zinc transporter 3 , ZnT3, were negatively correlated with soluble $A \beta(p<0.01)$. These findings are particularly relevant because increased intake of dietary supplements, such as Zn, are common in the elderly - a population already at risk for AD. Given the effects observed in the CRND8/E4 mice, ApoE status should be taken into consideration when evaluating the efficacy of therapies targeting metals.

Keywords: apolipoprotein E, hAPP, CRND8, transgenic mice, Barnes maze, metals, ZnT3, copper

\section{INTRODUCTION}

Alzheimer's disease (AD) is the primary cause of dementia in the elderly and currently affects more than five million Americans (Alzheimer's Association, 2013). The present research focuses on how the biometals, such as zinc $(\mathrm{Zn})$, copper $(\mathrm{Cu})$, and iron $(\mathrm{Fe})$, interact with amyloid beta $(\mathrm{A} \beta)$ - the key constituent of the plaques that are characteristic of the disease, which mediates plaque formation and consequent oxidative damage.

$\mathrm{Zn}, \mathrm{Cu}$, and $\mathrm{Fe}$ are found in high concentrations in and around amyloid plaques (Lovell et al., 1998; Maynard et al., 2005), consistent with the notion that $A \beta$ is a metalloprotein that possesses binding sites for both $\mathrm{Zn}$ and $\mathrm{Cu}$ (Bush et al., 1993; Hesse et al., 1994). Zn has been shown to be particularly effective in promoting $A \beta$ aggregation (Bush et al., 1993), and the sequestration of $\mathrm{Zn}$ by $\mathrm{A} \beta$ leads to an intracellular deficiency of this metal (Grabrucker et al., 2011). Cu, on the other hand, causes a shift in the processing of the amyloid precursor protein (APP) towards the non-amyloidogenic pathway (Borchard et al., 1999) but once $A \beta$ is present, it binds both $\mathrm{Cu}$ and Fe. Therefore, $\mathrm{Cu}$ and Fe binding is problematic as these metals are redox-active and $\mathrm{A} \beta$ reduces both metals, resulting in the production of hydrogen peroxide $\left(\mathrm{H}_{2} \mathrm{O}_{2}\right.$; Huang et al., 1999). $\mathrm{H}_{2} \mathrm{O}_{2}$ further reacts with the reduced metal to produce hydroxyl radicals that can cause oxidative damage (Bush, 2003). Both aging and plaque-related inflammation may promote a more acidic brain environment, which is conducive to Fe and/or Cu binding (Atwood et al., 1998).

Evidence suggests that $\mathrm{Zn}$ is crucial for $\mathrm{A} \beta$ deposition, and the presence of $\mathrm{Zn}$ in vitro prevents the proteolytic degradation of $\mathrm{A} \beta_{1-42}$ by matrix metalloprotease 2 (Crouch et al., 2011). Zn also inhibits the activity of alpha-secretase and promotes gamma- and beta-secretase activity (Capasso et al., 2005). The zinc transporter, $\mathrm{ZnT3}$, is responsible for loading zinc into the synaptic vesicles 
(Palmiter et al., 1996; Cole et al., 1999; Linkous et al., 2008). Eliminating synaptic $\mathrm{Zn}$ by genetic ablation of zinc transporter 3 ( $\mathrm{ZnT} 3)$ in an $\mathrm{AD}$ mouse model resulted in a $50 \%$ reduction in amyloid (Lee et al., 2002). ZnT3 levels, however, have been shown to decrease as a function of age and AD (Adlard et al., 2010). Interestingly, Bjorklund et al. (2012) found that in brains exhibiting AD neuropathology, ZnT3 levels were lowest in those patients who received a diagnosis of $\mathrm{AD}$, while those who did not receive a diagnosis had $\mathrm{ZnT} 3$ levels similar to those of healthy controls.

Given the complexity of biometals in $\mathrm{AD}$, the behavioral outcome due to changes in metal levels is difficult to predict, but this has been studied in various mouse models. Long-term dietary $\mathrm{Zn}$ enhancement in transgenic (Tg) mouse models of AD (TgCRND8, Tg2576, and APP/presenilin 1 (PS1) mouse models) has been shown to result in cognitive deficits (Linkous et al., 2009; Railey et al., 2011), as well as an increase in both brain $\mathrm{Zn}$ levels and the number and size of $\mathrm{Zn}$-positive plaques in the cortex and hippocampus (Wang et al., 2010). Other findings have found that a severe $\mathrm{Zn}$ deficiency ( $<10 \mathrm{ppm} \mathrm{Zn}$ ) enlarged amyloid plaques (Stoltenberg et al., 2007); thus either an overabundance or deficiency in $\mathrm{Zn}$ can potentiate amyloid deposition.

The observations derived from these early-onset mouse models may be of diminished utility for the majority of $\mathrm{AD}$ cases that are classified as late-onset (manifest after age 65 years) (Harvey et al., 2003). The emphasis on early-onset genetics dominating $\mathrm{AD}$ research is due to the strong relationship between those genes and development of the disease. Genetic linkages to the late-onset form of $\mathrm{AD}$ are less specific, but the $\varepsilon 4$ allele of the apolipoprotein $\mathrm{E}$ (ApoE) gene has been identified as a major risk factor (Saunders et al., 1993; Blacker et al., 1998; Huang and Mucke, 2012). The ApoE gene has three alleles $(\varepsilon 2, \varepsilon 3$, and $\varepsilon 4)$ resulting in three isoforms of the protein (Zannis et al., 1981), with ApoE $\varepsilon 4$ overrepresented in patients with late-onset AD (Weisgraber and Mahley, 1996). While ApoE $\varepsilon 4$ is considered a susceptibility factor it does not guarantee the development of disease (Weisgraber and Mahley, 1996). The exact mode of action of ApoE $\varepsilon 4$ in $\mathrm{AD}$ remains elusive. One proposed mechanism is the interaction between ApoE $\varepsilon 4$ and $A \beta$, which may increase plaques and/or impede $A \beta$ clearance (Mahley et al., 2006). Amongst those with $\mathrm{AD}, \mathrm{ApoE} \varepsilon 4$ carriers typically have a larger number of plaques than ApoE $\varepsilon 3$ carriers (Schmechel et al., 1993). Similarly, ApoE $\varepsilon 4$ mice that overexpress human APP have an elevation in $A \beta$ plaque deposition, reduced numbers of presynaptic terminals, and an impairment in learning and memory tasks as compared to their $\varepsilon 3$ counterparts (Huang, 2006).

The ApoE alleles differ at two residues: $\varepsilon 2$ ( Cys $\left.^{112}, \mathrm{Cys}^{158}\right), \varepsilon 3$ (Cys $\left.{ }^{112}, \operatorname{Arg}^{158}\right)$, and $\varepsilon 4$ ( $\operatorname{Arg}^{112}, \operatorname{Arg}^{158}$ ) (Rebeck et al., 2002). Cysteine binds to $\mathrm{Zn}$ and $\mathrm{Cu}$ with high affinity and the $\mathrm{Zn}$ binding site on APP is located in a cysteine-rich area (Bush and Tanzi, 2002). The increased number of cysteine residues in $\varepsilon 2$ and $\varepsilon 3$ correlates with their ability to bind zinc in the synaptic cleft and may contribute to the protective effect of these alleles by preventing zinc binding to $A \beta$ (Lee et al., 2010). ApoE $\varepsilon 4$ is also implicated in the formation of neurofibrillary tangles (NFTs). It may increase the phosphorylation of the tau protein (Harris et al., 2004) and Zn may be a key modulator of this process (Craddock et al., 2012).
Through their relatively high-binding affinity for zinc, $A \beta$ plaques will cause a reduction in intracellular levels of zinc that will in turn lead to a destabilization of microtubules and subsequent liberation of tau (Craddock et al., 2012). These findings suggest that $\mathrm{Zn}$ and ApoE $\varepsilon 4$ may act together to affect multiple processes in $\mathrm{AD}$ through the promotion of NFT formation and increased $\mathrm{A} \beta$ deposition, which may be due to increased $\mathrm{Zn}$ binding in the presence of ApoE $\varepsilon 4$.

In order to examine the effect of excess zinc in the more prevalent form of $\mathrm{AD}$ we have developed a late-onset model, examining two types of $\mathrm{Tg}$ mice with the (1) humanized ApoE $\varepsilon 4$ and mutated hAPP cross (CRND8/E4); or (2) those only with mutated hAPP (CRND8), and investigated the effect of $\mathrm{Zn}$ supplementation on spatial memory in these mice. Protein levels of soluble and insoluble $\mathrm{A} \beta$, and $\mathrm{ZnT} 3$ were measured to elucidate molecular mechanisms that may be associated with excess dietary zinc in $\mathrm{AD}$.

\section{MATERIALS AND METHODS SUBJECTS}

To address the primary research questions of the study, the creation of a mouse strain modeling late-onset $\mathrm{AD}$ was necessary. The CRND8/E4 experimental animals were obtained by breeding CRND8 males (University of Toronto) with female mice who were homozygous for the human ApoE $\varepsilon 4$ knock-in and the knockout of murine ApoE (Jackson Labs). Resultant CRND8/E4 were therefore heterozygous for human ApoE $\varepsilon 4$ and murine ApoE in addition to being hemizygous for the hAPP mutation. Tg CRND8 mice carry a mutant form of APP 695 containing both the Swedish (KM670/671NL) and Indiana (V717F) mutations on a hybrid $\mathrm{C} 3 \mathrm{H} / \mathrm{B} 6$ genetic background and exhibit extensive amyloid deposition by 3 months of age. There is a potent increase in $\mathrm{A} \beta_{42}$ at around 10 weeks of age in this model making the $A \beta_{42}$ to $A \beta_{40}$ ratio 5:1 (Chishti et al., 2001). The Tg1HolApoe ${ }^{\text {tml } 1 \text { unc } / J}$ strain expresses human ApoE $\varepsilon 4$ under the direction of human glial fibrillary acidic protein (GFAP). Experimental WT mice were those littermates who did not inherit the hAPP transgene from the cross between CRND8 males and WT females (C3H/B6). CRND8 mice were those offspring who inherited the hAPP transgene from the CRND8 males that were bred with WT females.

Mice were bred in three groups in order to facilitate behavioral testing. The offspring were group housed with same-sex littermates with 2-4 animals per cage. Each cage contained an igloo, nylabone, and running wheel (Bio-serv). The mouse colony was maintained with a 12-h light/dark cycle. Food (Harlan diet 7012) and water were provided ad libidum.

Behavioral group numbers are shown in Table 1. This study used both male and female mice, and analyses were conducted to determine possible sex differences. $\mathrm{Zn}$ supplementation began at 6 weeks of age and continued throughout behavioral testing. Behavioral testing began at 5 months of age and mice were sacrificed within 10 days following the conclusion of all behavioral testing (approximately 6 months of age). Mice were euthanized by $\mathrm{CO}_{2}$ asphyxiation and brains were removed and stored in a $-80^{\circ}$ freezer for later analysis. There were no differences in body weight on the day of euthanasia when evaluated by water condition. All experiments and procedures performed on these mice were 
Table 1 | Group distributions and male to female ratio for Barnes maze (BM) and Western blot (WB) analyses.

\begin{tabular}{lcccc}
\hline Group & BM $\boldsymbol{N}=$ & BM m:f & WB $\boldsymbol{N}=$ & WB m:f \\
\hline WT + Lab Water & 12 & $7: 5$ & 0 & $\mathrm{n} / \mathrm{a}$ \\
WT + Zn & 12 & $6: 6$ & 0 & $\mathrm{n} / \mathrm{a}$ \\
CRND8/E4 + Lab Water & 11 & $6: 5$ & 10 & $5: 5$ \\
CRND8/E4 + Zn & 11 & $5: 6$ & 11 & $5: 6$ \\
CRND8 + Lab Water & 12 & $8: 4$ & 10 & $6: 4$ \\
CRND8 + Zn & 11 & $9: 2$ & 9 & $7: 2$ \\
\hline
\end{tabular}

approved by the George Mason University Institutional Animal Care and Use Committee.

\section{WATER PREPARATION}

The 10 ppm $\mathrm{ZnCO}_{3}$ was supplemented to laboratory tap water (herein referred to as $\mathrm{Zn}$ water) and was prepared using a starting solution of $10,000 \mathrm{mg} / \mathrm{L}$ of zinc dissolved in $5 \% \mathrm{HNO}_{3}$. The final solution was buffered with $\mathrm{Na}_{2} \mathrm{CO}_{3}$ to bring it to a $\mathrm{pH}$ of 7.0 (Linkous et al., 2009). All waters were made and stored in separate polycarbonate carboys and dispensed to animals in $500 \mathrm{~mL}$ glass bottles. Water was analyzed regularly using inductively coupled plasma-optical emission spectroscopy and ion chromatography at the United States Geological Survey (USGS, Reston, VA) to confirm metal content. Laboratory tap water without any supplement, herein referred to as lab water, was used for the control group. Water consumption was measured every week and there were no significant differences when evaluated by water condition.

\section{BARNES MAZE}

The Barnes maze (BM) is designed to assess spatial memory. The maze (Med Associates) consisted of an elevated platform $122 \mathrm{~cm}$ in diameter ( $91 \mathrm{~cm}$ above the ground) with 40 equidistant holes located around the edges. The maze's surface color was white. An escape box was located under one of the holes and four distinctive extra-maze reference cues were placed around the maze, with one on each side (large black letters on a white background). Testing took place in a brightly illuminated room with a 300 -watt light situated directly over the maze in order to make the maze surface undesirable, given the natural tendency of mice to prefer dark enclosed areas over bright/open areas. All animals started each trial from a dark enclosed start box positioned in the center of the maze. The orientation of the start chamber was varied for each trial. The maze was cleaned with $70 \%$ ethanol solution between all trials to eliminate scent trails.

\section{Procedure}

BM testing took place over seven consecutive days with the 24-h probe trial occurring on the seventh day.

Habituation: On the first day of testing all mice were given two habituation trials. The mice were placed in a start chamber in the center of the maze for $10 \mathrm{~s}$ after which time the start box was lifted and they were gently guided to the escape box and allowed to enter on their own. Once inside, mice stayed in the escape box for $30 \mathrm{~s}$ before being returned to their home cage for a 2 min inter-trial interval.
Acquisition: Days 2-6 were acquisition days. The mice received three trials per day with a $15 \mathrm{~min}$ inter-trial interval. The trials on the acquisition days ended when the animal entered the escape box or when the maximum trial length of 3 min was reached. Mice were allowed $30 \mathrm{~s}$ in the escape box after locating it. If the animal did not find the escape box in the allotted 3 min trial period they were gently guided to the escape box and allowed $30 \mathrm{~s}$ inside. Primary latency (amount of time elapsed prior to first reaching target hole) and primary errors (number of errors made prior to reaching target hole) were measured.

Probe Trial: On day 7 the animals received one probe trial $24 \mathrm{~h}$ after the last training trial. The escape box was removed from the target hole that had been previously learned and the mice were given $3 \mathrm{~min}$ to explore the maze. Percent of time in the correct quadrant was measured.

\section{TISSUE PREPARATION}

Frozen brain samples were minced into small pieces and homogenized in $1 \mathrm{~mL}$ of a mixture of PBS and protease/phosphatase inhibitor cocktail (Sigma-Aldrich). The homogenate was then centrifuged at $4^{\circ} \mathrm{C}$ at 24,000 RPM for $1 \mathrm{~h}$. Soluble and insoluble fractions were separated. The insoluble fractions were additionally reconstituted in $1 \mathrm{~mL}$ of a mixture of PBS and protease/phosphatase inhibitors. Both soluble and insoluble fractions were then lyophilized for approximately $12 \mathrm{~h}$ until fully dehydrated.

\section{WESTERN BLOT ANALYSES}

For Western blot (WB) analysis, lyophilized insoluble fractions were reconstituted in $250 \mu \mathrm{L}$ of PBS and protease/phosphatase inhibitor cocktail. Soluble fractions were reconstituted in $50 \mu \mathrm{L}$ of PBS and cocktail. A BCA protein assay was done to determine protein concentration for each sample. Fifteen microliters of samples were heated at $90^{\circ} \mathrm{C}$ for $10 \mathrm{~min}$ and then spun down and loaded onto Criterion XT precast $4-12 \%$ gels. After the gels were run and transferred to a PVDF membrane they were blocked in $5 \%$ tris buffered saline with Tween 20 (TBST) skim milk for $1 \mathrm{~h}$. The membranes were then briefly rinsed with TBST and incubated overnight at $4^{\circ} \mathrm{C}$ with the following primary antibodies: WO2 (1:2000; in-house antibody prepared at The Florey Institute of Neuroscience and Mental Health); ZnT3 (1:10,000, inhouse antibody prepared at The Florey Institute of Neuroscience and Mental Health); and GAPDH (1:10,000; Millipore Cat: MAB 374). After three washes of TBST for 5-10 min, secondary antibody incubation was performed (polyclonal rabbit anti-mouse IgG conjugated to horseradish peroxidase (HRP); 1:10,000; Dako $\mathrm{P} 0260)$ at room temperature for $1 \mathrm{~h}$. Three additional washes of TBST were done before enhanced chemiluminescent substrate was added for imaging using Multigauge software (Fujifilm). After imaging, the membranes were briefly rinsed with TBST and then the membranes were stripped using Re-blot Plus Strong solution (Millipore). The bands were scanned and the intensities of the bands were measured using the Fuji Reader LAS-4000. Protein levels for WO2 and ZnT3 were normalized to GAPDH (Figure 5). 


\section{STATISTICAL ANALYSES}

Statistical differences among different genotypes and water conditions against measured behavioral parameters were determined by repeated-measures analysis of variance (RMANOVAs). When necessary, Greenhouse-Geisser estimates of sphericity were used to correct for degrees of freedom. Bonferroni post-hoc tests were used to evaluate group differences. Correlations between protein levels and measured behavioral parameters were calculated using the Pearson correlation coefficient $(r)$. Data are expressed as mean \pm SEM. A significance level of $p<0.05$ was used for all analyses. Trends were reported at a level of $p<0.10$.

\section{RESULTS}

\section{BARNES MAZE BEHAVIOR}

Three genotypes (WT, CRND8/E4, CRND8) $\times$ two water conditions (lab water and zinc water) mixed design RMANOVAs were performed for measures of primary latency, primary errors, and percent of time in the target quadrant for the 24-h probe trial. Between group variables were genotype and water type. The within subjects variable was testing day (five levels). Sex was entered as a covariate for all statistical analyses.

On days 1-5, there was a significant within-subjects effect of day for primary latency $\left(F_{(3.03,172.43)}=44.29, p<0.001\right)$ indicating overall improvement across testing days for all groups. There was a significant effect on primary latency between genotypes $\left(F_{(2,57)}=4.124, p<0.05\right)$. A Bonferroni post-hoc test revealed that primary latencies across days $1-5$ were significantly shorter for WT mice as compared to CRND8 mice $(p<0.05)$, but not compared to CRND8/E4. The CRND8/E4 were also not significantly different from CRND8 mice (Figure 1A). On average CRND8/E4 animals had latencies that were shorter than CRND8 animals, but longer than WT animals. For primary latency, there were no main effects of water condition.

On days 1-5, there was a significant within-subjects effect of day for primary errors $\left(F_{(3.39,200.0)}=23.32, p<0.001\right)$. For primary errors there were no significant main effects of water or genotype across all groups on days $1-5$ or during probe trials (Figure 1B). Further analyses within genotypes revealed no significant differences between Zn water and lab water in WT and CRND8 mice (Figures 2A,B). However, within the CRND8/E4 genotype there was a significant main effect of water. CRND8/E4 mice on $\mathrm{Zn}$ water made significantly more primary errors than those CRND8/E4 on lab water on days $2-3\left(F_{(1,17)}=5.64\right.$, $p<0.05$; Figure 2C).

There were no significant main effects of genotype on the 24-h probe trial. There was, however, a significant main effect of water condition within the WT group. Zn water WT mice spent significantly less time than lab water WT mice in the target (correct) quadrant ( $23 \%$ vs. $41 \%$ respectively) $\left(F_{(1,21)}=3.28\right.$, $p<0.05$; Figure 3). Both CRND8/E4 and CRND8 groups raised on either $\mathrm{Zn}$ or lab water scored close to chance during the probe trial.

In summary, there were significant main effects of water condition within the CRND8/E4 and WT genotypes, but not in the CRND8 group. As predicted, Zn water CRND8/E4 mice had higher primary errors in the BM compared to those on lab water. Significant genotype differences did exist between CRND8

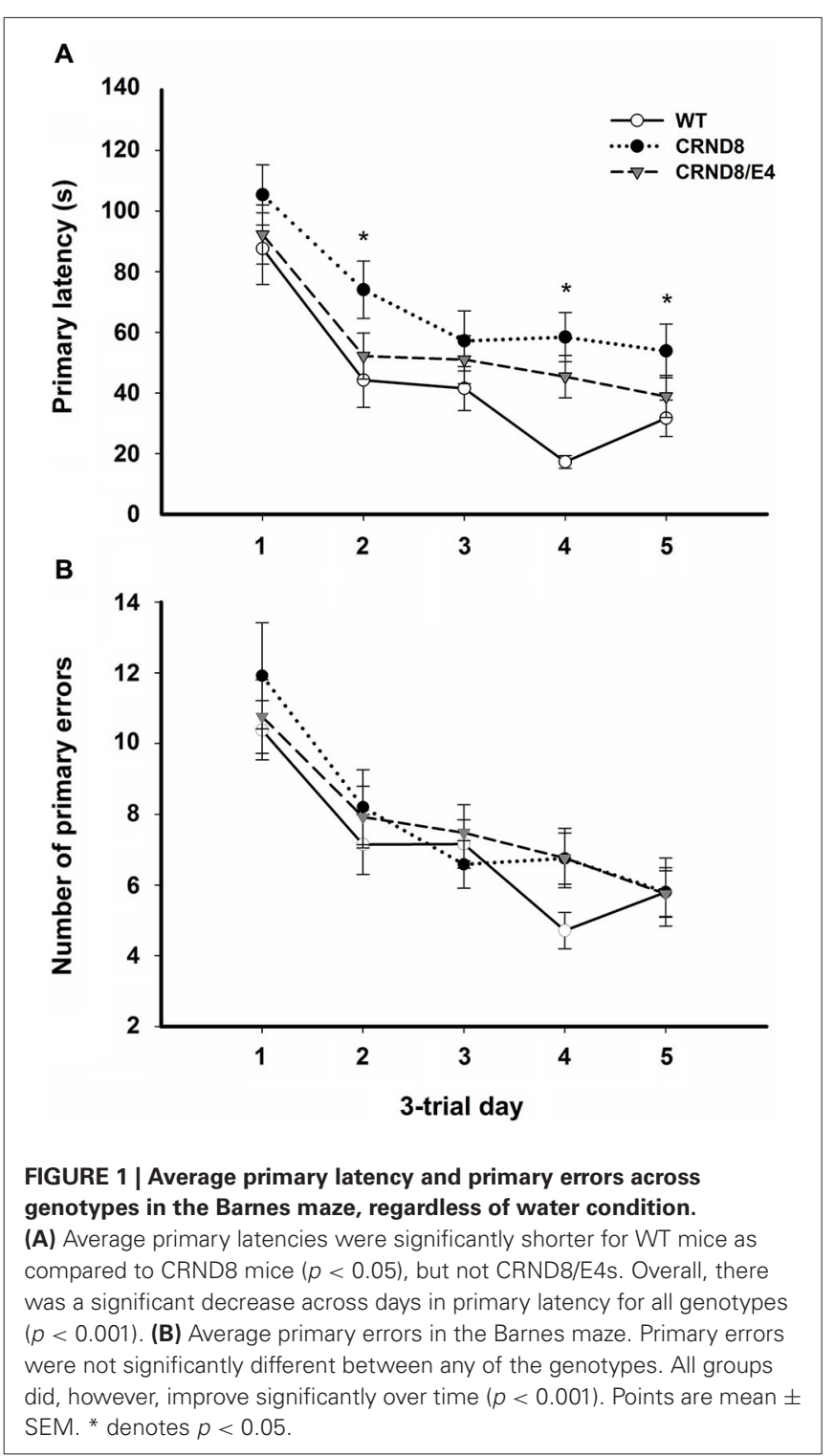

mice compared to WT mice on measures of primary latency, as was expected. Mice carrying both the ApoE $\varepsilon 4$ and mutated hAPP genes were not more impaired than the CRND8 transgene. However, on the primary error measure, CRND8/E4 mice on $\mathrm{Zn}$ water had the highest number of primary errors. WT mice on $\mathrm{Zn}$ water were spent significantly less time in the target quadrant when compared to those WTs on lab water.

\section{PROTEIN ANALYSIS}

Relative levels of soluble $\mathrm{A} \beta$, insoluble $\mathrm{A} \beta$, and ZnT3 were obtained from WB analysis. This analysis was conducted only on Tg mice (CRND8 and CRND8/E4). The control for both Tg groups was a CRND8/E4 in the lab water group which may explain why all significant correlations with behavior were seen only in the CRND8/E4 group; all protein correlations presented here are within that genotype only. There were no significant main effects for water and genotype. There were no significant main effects on levels of ZnT3. There were also no 


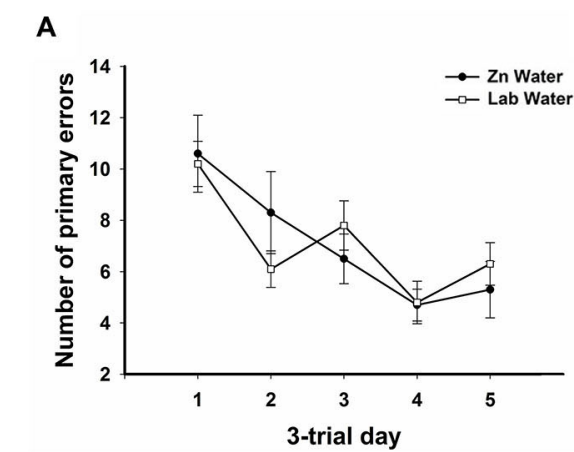

B

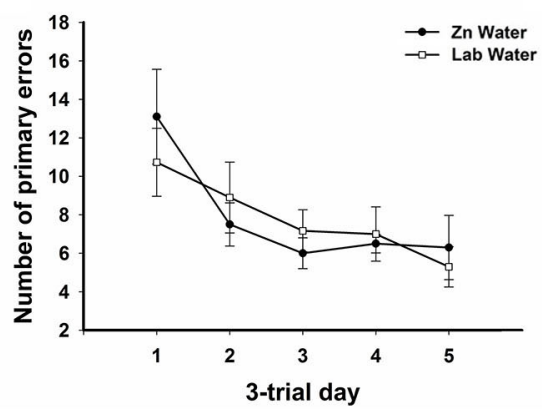

C

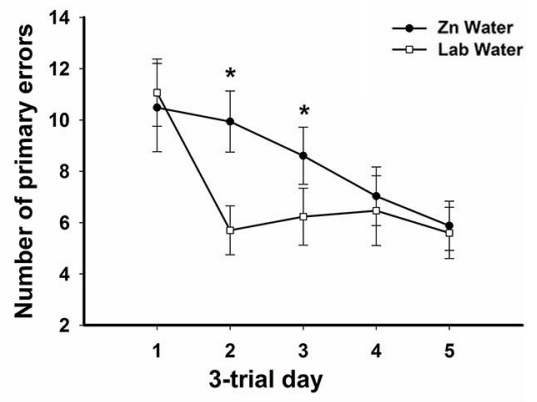

FIGURE 2 | Average primary errors for all genotypes. There were no significant differences between Zn and Lab water (A) WT and (B) CRND8 mice. (C) Within the CRND8/E4 mice, however, those on Zn water had significantly more primary errors than the lab water group on days 2 and 3 ( $p<0.05$ ). Points are mean \pm SEM. * denotes $p<0.05$.

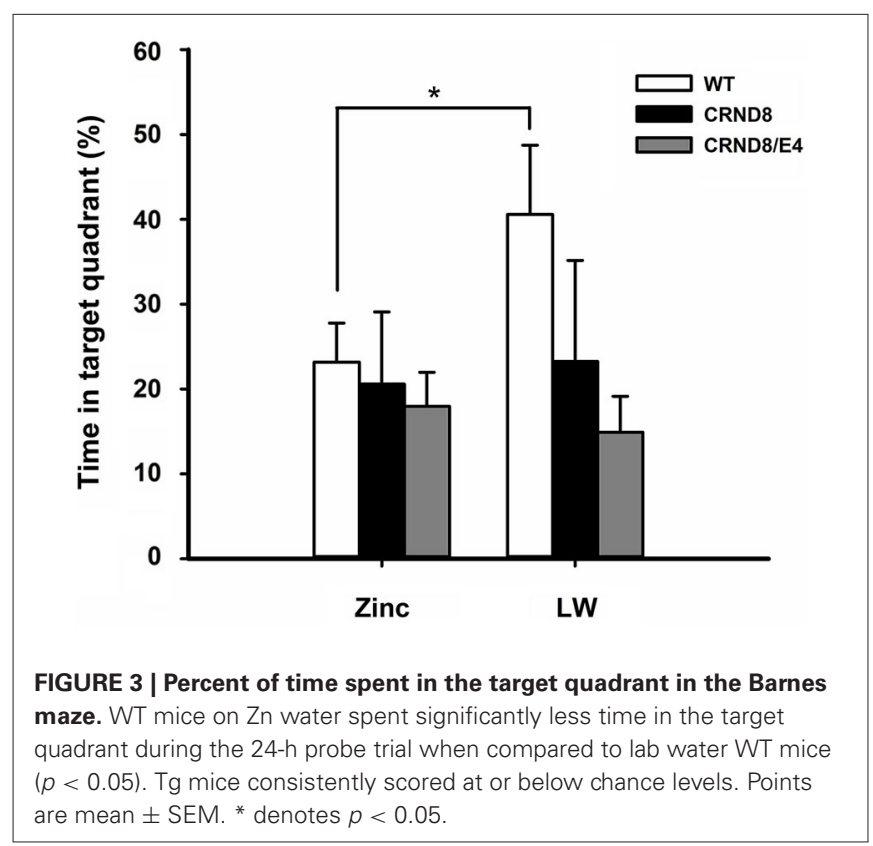

significant main effects for soluble $\mathrm{A} \beta$ or insoluble $\mathrm{A} \beta$. Regardless of water condition, however, levels of soluble $A \beta$ were significantly correlated with the average primary latencies for day $3(r=0.657$, $p<0.01)$ and day $4(r=0.463, p<0.05$; Figure 4A). Those mice on $\mathrm{Zn}$ water had levels of insoluble $\mathrm{A} \beta$ that were significantly correlated with average primary errors for day $3(r=0.754, p<$ $0.01)$ and day $5(r=0.658, p<0.05$; Figure $4 \mathrm{~B})$. Those on control lab water had soluble $A \beta$ levels which significantly correlated with the average primary latency on day $3(r=0.712, p<0.05$; Figure 4C). Mice on $\mathrm{Zn}$ water had levels of soluble $\mathrm{A} \beta$ that were negatively correlated with levels of $\mathrm{ZnT3}(r=-0.791, p<0.01$; Figure 4D).

\section{DISCUSSION}

These data show that the performance of the mice modeling lateonset $\mathrm{AD}$ depended significantly upon the presence or absence of $\mathrm{Zn}$ in the drinking water. Overall, CRND8/E4 mice did not perform worse than the CRND8 mice, as had initially been predicted. However, CRND8/E4 mice raised on $\mathrm{Zn}$ water made the most errors in the BM of all six groups, and also had significantly increased errors compared to those raised on lab water. On the primary latency measure, the CRND8 mice performed significantly worse than the WT mice. The CRND8/E4 group's performance was intermediate between the other groups, and did not differ significantly from either. In contrast to the effect on primary errors, there was no significant effect of $\mathrm{Zn}$ water on primary latency. The observation that primary errors, and not primary latencies, detected a $\mathrm{Zn}$ effect in the late-onset mouse model is consistent with O'Leary and Brown (2013) who have suggested that errors are a more sensitive measure of memory than latency in the Barnes maze.

The effect on errors may be due to enhanced $\mathrm{Zn}$ binding to $\mathrm{A} \beta$ when in the presence of ApoE $\varepsilon 4$. ApoE $\varepsilon 4$ has the weakest affinity for binding $\mathrm{Zn}$, due to the amino acid substitution of arginine which is not a ligand for $\mathrm{Zn}$ (Lee et al., 2010). In contrast, the ApoE $\varepsilon 2$ and $A p o E \varepsilon 3$ isoforms with cysteine residues strongly bind $\mathrm{Zn}$, and may prevent it from binding with $\mathrm{A} \beta$, which could in turn prevent oligomerization and deposition (Lee et al., 2010). While there are numerous in vitro studies investigating the association between $\mathrm{Zn}$ and ApoE $\varepsilon 4$, this is a novel behavioral study examining the relationship between the two in a mouse model of late-onset AD.

$\mathrm{Zn}$ water did not result in significant latency deficits in the CRND8 and WT groups. For the WT group, Zn significantly reduced the percent time spent in the target quadrant for the 24-h probe trial; thus the WT mice on $\mathrm{Zn}$ water were impaired on the most difficult memory task. Neither the CRND8/E4 or CRND8 groups performed above chance on either water condition (Figure 4); thus, additional impairments caused by $\mathrm{Zn}$ were difficult to assess. Given the difficulty of the 24 -h probe task for the Tg mice, running probe tests as the last run on alternate days, as is done in the Morris water maze (MWM), could be a useful strategy.

We have previously demonstrated significant latency impairments in the MWM in both Zn water rats and Tg (CRND8 and 

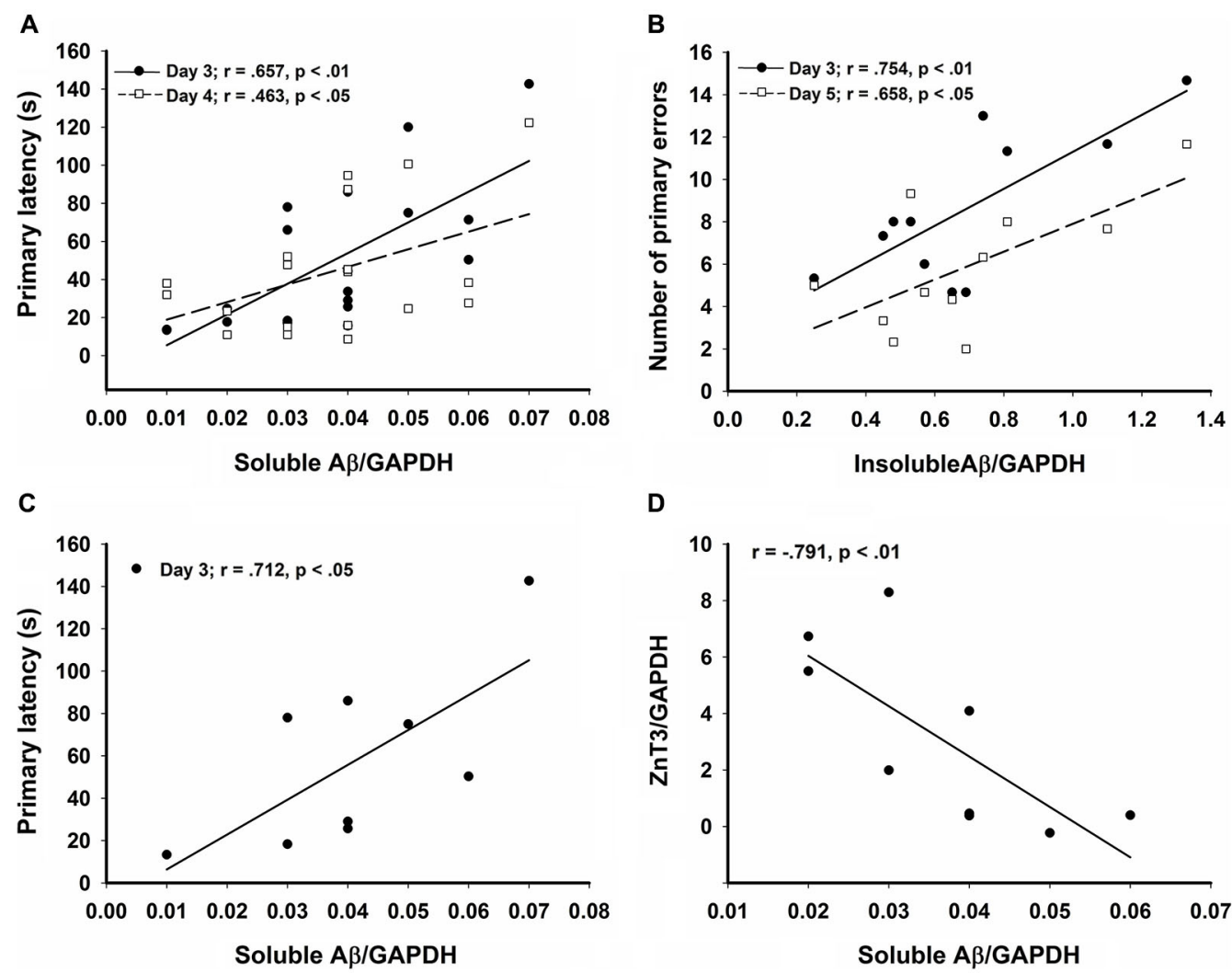

D

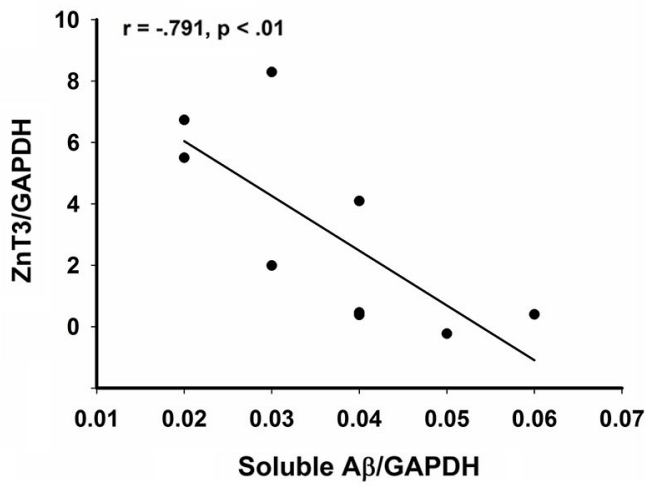

FIGURE 4 | Significant correlations in the CRND8/E4 group showing (A) soluble $A \beta$ vs. average primary latencies for days 3 $(r=0.657, p<0.01)$ and $4(r=0.463, p<0.05)$; (B) In Zn water mice, insoluble $A \beta$ vs. average primary errors for days 3 ( $r=0.754$,

$p<0.01)$ and $5(r=0.658, p<0.05)$; (C) In lab water mice, soluble $A \beta$ vs. average primary latency on day $3(r=0.712, p<0.05)$; and (D) In Zn water mice, soluble A $\beta$ negatively correlates with ZnT3 ( $\boldsymbol{r}=-\mathbf{0 . 7 9 1 ,} \boldsymbol{p}<\mathbf{0 . 0 1}$ ). * denotes $p<0.05$.

Tg2576) mice (Linkous et al., 2009; Railey et al., 2010, 2011). The MWM is a more stressful test than the BM (Hölscher, 1999) and this may account for the different effects of zinc on latency seen in this experiment. Overall, data from our lab indicate that $\mathrm{Zn}$ water has adverse behavioral effects on WT and CRND8 mice but that additional mechanisms are at work for CRND8/E4 mice. Although Zn supplementation exacerbated behavioral deficits in the Tg2576 and CRND8 mice, this led to a paradoxical decrease in amyloid deposits in the Tg2576 mice (Linkous et al., 2009), which was also observed by Harris et al. (2014); however they found no significant behavioral differences.

The deficits in spatial memory that were observed in the Barnes maze, in connection with dietary $\mathrm{Zn}$ supplementation, may be attributable to the effect of $\mathrm{Zn}$ on other metals in the brain, specifically $\mathrm{Cu}$. Excess dietary $\mathrm{Zn}$ prevents adequate absorption of $\mathrm{Cu}$ through the intestinal wall (Milne et al., 2001). Therefore, $\mathrm{Zn}$ supplementation may potentiate a $\mathrm{Cu}$ deficiency that is inherent in Tg mice overexpressing mutant hAPP (Phinney et al., 2003). Brewer (2014), however, found a nonsignificant delay in cognitive impairment in $\mathrm{AD}$ patients who received $\mathrm{Zn}$ supplements, and suggests that $\mathrm{AD}$ is the result of a $\mathrm{Zn}$ deficiency. He also noted that these subjects had relatively low $\mathrm{Zn}$ serum levels and suggested that this would lead to an overload of copper. Brewer (2014) considers zinc deficiency a risk factor for $\mathrm{AD}$, due to its interaction with copper (Brewer, 2014).

In contrast, Klevay (2008) has suggested that AD is due to a $\mathrm{Cu}$ deficiency instead of $\mathrm{Cu}$ toxicity and spatial memory deficits in Zn-treated Tg mice can be remediated by the concurrent administration of small amounts of $\mathrm{Cu}$ (Railey et al., 2011). APPoverexpressing mice have lower levels of $\mathrm{Cu}$ in the brain (Bayer et al., 2003) which would support increasing dietary $\mathrm{Cu}$ to treat $\mathrm{AD}$. This is consistent with another study where APP23 mice were given $\mathrm{Cu}$ supplementation which resulted in a reduction of $\mathrm{A} \beta$ and an increase in superoxide dismutase 1 (SOD1) activity (Bayer et al., 2003). These conflicting findings from different labs suggest that metal dyshomeostasis in $\mathrm{AD}$ can be due to either a deficiency or overabundance of metal ions, and that alterations to the levels of one metal can impact levels of another. The initial metal status of the patient should be an important factor in considering any form of dietary metal-based therapy.

In contrast to our observations, $\mathrm{Zn}$ supplementation in the 3xTg mouse actually improved performance on behavioral tasks, and decreased both $\mathrm{A} \beta$ and tau pathology (Corona et al., 2010), while decreased dietary $\mathrm{Zn}$ elevated plaque volume in APP/PS1 mice (Stoltenberg et al., 2007). Carrying mutations in PS1, or 


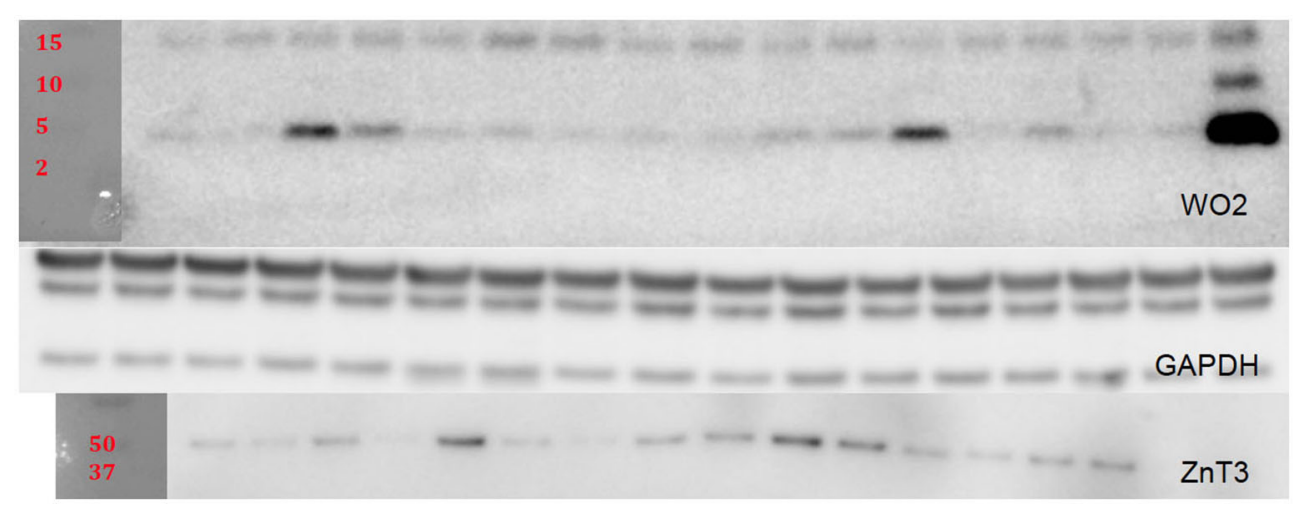

FIGURE 5 | Representative blots are shown for WO2 and ZnT3 which were normalized to GAPDH.

in the case of the $3 \times \mathrm{Tg}$, a mutation in tau, can alter the ability of these proteins to interact with metals. The divergent results may stem from differences in the mouse model used, chemical composition of zinc solutions, and age of onset and duration of $\mathrm{Zn}$ supplementation. Our mice were given a standard rodent chow which contains adequate levels of $\mathrm{Zn}$, in addition to the $\mathrm{Zn}$ supplementation, which would be in contrast to the $\mathrm{Zn}$ deficiency that is reported in the elderly population. While $\mathrm{Zn}$ therapy may be beneficial for those with a $\mathrm{Zn}$ deficiency, excess $\mathrm{Zn}$, and $\mathrm{Zn}$ in the presence of ApoE \&4, may actually be harmful.

In a mouse model carrying the three different human ApoE alleles in the 5xTg mouse, the ApoE transgenes delayed pathology typically observed in the 5xTg strain (Youmans et al., 2012). Although having an expanded window of time to study the progression of $\mathrm{AD}$ pathology could be useful, using either the $3 \mathrm{xTg}$ or $5 \mathrm{xTg}$ strains may be contraindicated for studying the effects of $\mathrm{Zn}$ or other metals in late-onset AD. These multiple transgene models have mutations in PS1, which affects cellular turnover of $\mathrm{Zn}$ and $\mathrm{Cu}$, since PS1 has $\mathrm{Zn}$ binding sites, which will affect SOD1 activity (Sensi et al., 2008; Greenough et al., 2011; Southon et al., 2013). Therefore, studies looking at the relationship between metals and pathobiology of late-onset $\mathrm{AD}$ should avoid incorporating mutated PS1 transgenes. Also, enzymes that modulate tau are $\mathrm{Zn}$ dependent.

The current data did not support the predicted outcome of more behavioral impairment in CRND8/E4 mice as compared to CRND8 mice. On most measures the CRND8/E4 mice performed slightly, but not significantly, better than CRND8 mice. This is consistent with other recent behavioral data in younger Tg mice modeling late-onset AD (Moreau et al., 2013). Similar observations of intermediacy were reported in circadian rhythm and nest building behavior, as well as in markers for inflammatory cytokines (Graybeal et al., 2014). Recent studies have shown that any isoform of human ApoE delays AD pathology in early-onset Tg mice (Youmans et al., 2012; Tai et al., 2013).

One possible explanation for the greater impairment associated with the ApoE $\varepsilon 4$ allele in old age is due to its interaction with metals and their dysregulation with increased age. $\mathrm{Zn}$ and $\mathrm{Cu}$ have an interdependent relationship and they exist in a delicate homeostasis whereby a shift towards either excess or deficiency may influence $A \beta$ neurotoxicity. Lee et al. (2012) have shown that $\mathrm{Zn}$ accumulates around dystrophic neurons in aged Tg2576 mice and suggest that this excess $\mathrm{Zn}$ "crowded around amyloid plaques" and could directly cause the death of neurons. Such an effect would likely be greater in the case of ApoE $\varepsilon 4$ which does not bind $\mathrm{Zn}$ and $\mathrm{Cu}$ as efficiently as the other forms of ApoE.

Another interesting finding was that ZnT3, which is the transporter responsible for loading zinc into synaptic vesicles, was negatively correlated with soluble $A \beta$ levels, which is the more toxic form of $A \beta$. Although a general decline in levels of $\mathrm{ZnT} 3$ has been associated with cognitive decline (Bjorklund et al., 2012), it has also been demonstrated that the regions of brain that express ZnT3 may change so that the overall level of expression remains unaltered, but the localization of expression may vary and be centered more around areas of pathology in the Tg CNS (Lee et al., 2012). This may explain why no overall differences for ZnT3 expression were detected. It is notable that within the $\mathrm{Zn}$ water group we observed a correlation between insoluble $A \beta$ and primary errors, as this may be due to the ability of $\mathrm{Zn}$ to aggregate $A \beta$. The relationship between amyloid load and learning and memory remains controversial; for example, Gruart et al. (2008) found no relationship between hippocampal-dependent learning and amyloid load, suggesting that other mechanisms may be involved.

ApoE ablation reduces the amount of ZnT3 and results in significantly lower levels of synaptic Zn compared to WTs (Lee et al., 2010). $\mathrm{Zn}$ is required for both presynaptic and postsynaptic mossy fiber long-term potentiation, and dysregulation of synaptic $\mathrm{Zn}$ alters the excitatory input of the mossy fiber-CA3 synapse in the hippocampus (Pan et al., 2011). Furthermore, ApoE- $\varepsilon 4$ targeted replacement mice have altered levels of glutaminase and vesicular glutamate transporter 1 (Dumanis et al., 2013). ApoE$\varepsilon 4$ is correlated with decreased dendritic spines (Dumanis et al., 2009), and treatment of neurons with ApoE- $\varepsilon 4$ recombinant protein reduces expression of glutamate receptors (Chen et al., 2010). Future research should examine the effects of $A \beta, Z n$ supplementation, and ApoE status on glutamatergic pathways. 
Since this study demonstrates that CRND8/E4 mice are sensitive to dietary $\mathrm{Zn}$-enhancement, this suggests that therapies targeting metals should consider ApoE allele status in their analyses. Currently, the only FDA-approved drugs for treating AD work by alleviating symptoms instead of targeting the underlying etiology of the disease. A newer class of drugs currently under evaluation, the 8-hydroxyquinolines (8-OHQ), are selective $\mathrm{Zn} / \mathrm{Cu}$ chaperones (Greenough et al., 2013). Two drugs in this class, Clioquinol (CQ) and PBT2 have a higher affinity for binding $\mathrm{Zn}$ and $\mathrm{Cu}$ when compared to $A \beta$. Instead of chelating these metals from the system, they are able to return metals back inside the cell, thereby restoring the bioavailability of metal ions necessary for cellular processes (Adlard and Bush, 2012). This restoration of intracellular metal concentrations has been shown to increase synaptic proteins, reduce $A \beta$ accumulation, and improve cognitive functioning in Tg mice (Adlard et al., 2008, 2011; Crouch et al., 2011).

\section{CONCLUSIONS}

This experiment showed that $\mathrm{Zn}$ water caused significant impairments in a mouse model of late-onset $\mathrm{AD}$, containing the ApoE $\varepsilon 4$ allele; consequently, studies on the role of metals in $\mathrm{AD}$ need to take into account the ApoE status of either the human subjects or the mouse models. Furthermore, due to the interaction between different metals such as $\mathrm{Cu}$ and $\mathrm{Zn}$, care needs to be taken when conducting both in vitro and in vivo studies, where the outcomes and interpretations of studies may be confounded by this interrelationship. Future studies examining the effects of $\mathrm{Zn}$ and/or $\mathrm{Cu}$ deficiencies and excesses in the different human ApoE alleles of a late-onset model of $\mathrm{AD}$ is warranted.

\section{ACKNOWLEDGMENTS}

The authors would like to thank Lara Glenn for assistance with many aspects of the study, Kathy Conko of USGS for analyzing water samples, Caroline L. C. Neely for manuscript edits, the University of Toronto for donating the CRND8 mice, and the reviewers of this manuscript for their helpful comments. This research was funded in part by a Sigma Xi GIAR and an APA dissertation research award to Angela M. Railey. Paul Anthony Adlard is supported by the NHMRC and ARC. In addition, the Florey Institute of Neuroscience and Mental Health acknowledges the strong support from the Victorian Government and in particular the funding from the Operational Infrastructure Support Grant. Publication of this article was funded in part by the George Mason University Libraries Open Access Fund.

\section{REFERENCES}

Adlard, P. A., Bica, L., White, A. R., Nurjono, M., Filiz, G., Crouch, P. J., et al. (2011). Metal ionophore treatment restores dendritic spine density and synaptic protein levels in a mouse model of Alzheimer's disease. PLoS One 6:e17669. doi: 10. 1371/journal.pone.0017669

Adlard, P. A., and Bush, A. I. (2012). Metal chaperones: a holistic approach to the treatment of Alzheimer'sdisease. Front. Psychiatry 3:15. doi: 10.3389/fpsyt.2012. 00015

Adlard, P. A., Cherny, R. A., Finkelstein, D. I., Gautier, E., Robb, E., Cortes, M., et al. (2008). Rapid restoration of cognition in Alzheimer's transgenic mice with 8hydroxy quinoline analogs is associated with decreased interstitial Abeta. Neuron 59, 43-55. doi: 10.1016/j.neuron.2008.06.018
Adlard, P. A., Parncutt, J. M., Finkelstein, D. I., and Bush, A. I. (2010). Cognitive loss in zinc transporter-3 knock-out mice: a phenocopy for the synaptic and memory deficits of Alzheimer's disease? J. Neurosci. 30, 1631-1636. doi: 10. 1523/JNEUROSCI.5255-09.2010

Alzheimer's Association. (2013). Alzheimer's disease facts and figures. Available online at: http://www.alz.org/alzheimers_disease_facts_and_figures.asp. Accessed on July 18, 2013.

Atwood, C. S., Moir, R. D., Huang, X., Bacarra, N. M., Scarpa, R. C., Romano, D. M., et al. (1998). Dramatic aggregation of Alzheimer $\mathrm{A} \beta$ by $\mathrm{Cu}(\mathrm{II})$ is induced by conditions representing physiological acidosis. J. Biol. Chem. 273, 1281712826. doi: $10.1074 /$ jbc. 273.21 .12817

Bayer, T. A., Schafer, S., Simons, A., Kemmling, A., Kamer, T., Tepest, R., et al. (2003). Dietary Cu stabilizes brain superoxide dismutase 1 activity and reduces amyloid Abeta production in APP23 transgenic mice. Proc. Natl. Acad. Sci. U S A 100, 14187-14192. doi: 10.1073/pnas.2332818100

Bjorklund, N. L., Sadagoparamanujam, V. M., Ghirardi, V., Woltjer, R. L., Taglialatela, G. N.L., and Reese, L. C. (2012). Absence of amyloid $\beta$ oligomers at the postsynapse and regulated synaptic $\mathrm{Zn} 2+$ in cognitively intact aged individuals with Alzheimer's disease neuropathology. Mol. Neurodegener. 7:23. doi: 10.1186/1750-1326-7-23

Blacker, D., Wilcox, M. A., Laird, N. M., Rodes, L., Horvath, M., Go, R., et al. (1998). Alpha-2 macroglobulin is genetically associated with Alzheimer's disease. Nat. Genet. 19, 357-360. doi: 10.1038/1243

Borchard, T., Camakaris, J., Cappai, R., Masters, C. L., Beyreuther, K., and Multhaup, G. (1999). Copper inhibits beta-amyloid production and stimulates the non-amyloidogenic pathway of amyloid-precursor-protein secretion. Biochem. J. 344, 461-467. doi: 10.1042/0264-6021:3440461

Brewer, G. J. (2014). Alzheimer's disease causation by copper toxicity and treatment with zinc. Front. Aging Neurosci. 6:92. doi: 10.3389/fnagi.2014.00092

Bush, A. I. (2003). The metallobiology of Alzheimer's disease. Trends Neurosci. 26, 207-214. doi: 10.1097/00002093-200307000-00005

Bush, A. I., Multhaup, G., Moir, R. D., Williamson, T. G., Small, D. H., Rumble, B., et al. (1993). A novel zinc (II) binding site modulates the function of the $\beta \mathrm{A} 4$ amyloid protein precursor of Alzheimer's disease. J. Biol. Chem. 268, 1610916112.

Bush, A. I., and Tanzi, R. E. (2002). The galvanization of $\beta$-amyloid in Alzheimer's disease. Proc. Natl. Acad. Sci. U S A 99, 7317-7319. doi: 10.1073/pnas.122249699

Capasso, M., Jeng, J. M., Malavolta, M., Mocchegiani, E., and Sensi, S. L. (2005). Zinc dyshomeostasis: a key modulator of neuronal injury. J. Alzheimers Dis. 8, 93-108; discussion 209-215.

Chen, Y., Durakoglugil, M. S., Xian, X., and Herz, J. (2010). ApoE4 reduces glutamate receptor function and synaptic plasticity by selectively impairing ApoE receptor recycling. Proc. Natl. Acad. Sci. U S A 107, 12011-12016. doi: 10. 1073/pnas.0914984107

Chishti, M. A., Yang, D., Janus, C., Phinney, A. L., Horne, P., Pearson, J., et al. (2001). Early-onset amyloid deposition and cognitive deficits in transgenic mice expressing a double mutant form of amyloid precursor protein 695. J. Biol. Chem. 276, 21562-21570. doi: 10.1074/jbc.m100710200

Cole, T. B., Wenzel, H. J., Kafer, K. E., Schwartzkroin, P. A., and Palmiter, R. D. (1999). Elimination of zinc from synaptic vesicles in the intact mouse brain by disruption of the ZnT3 gene. Proc. Natl. Acad. Sci. U S A 96, 1716-1721. doi: 10. 1073/pnas.96.4.1716

Corona, C., Masciopinto, F., Silvestri, E., Viscovo, A. D., Lattanzio, R., Sorda, R. L., et al. (2010). Dietary zinc supplementation of 3xTg-AD mice increases BDNF levels and prevents cognitive deficits as well as mitochondrial dysfunction. Cell Death Dis. 1:e91. doi: 10.1038/cddis.2010.73

Craddock, T. J. A., Tuszynski, J. A., Chopra, D., Casey, N., Goldstein, L. E., Hameroff, S. R., et al. (2012). The zinc dyshomeostasis hypothesis of Alzheimer's disease. PLoS One 7:e33552. doi: 10.1371/journal.pone.0033552

Crouch, P. J., Savva, M. S., Hung, L. W., Donnelly, P. S., Mot, A. I., Parker, S. J., et al. (2011). The Alzheimer's therapeutic PBT2 promotes amyloid- $\beta$ degradation and GSK3 phosphorylation via a metal chaperone activity. J. Neurochem. 119, 220-230. doi: 10.1111/j.1471-4159.2011.07402.x

Dumanis, S. B., DiBattista, A. M., Miessau, M., Moussa, C. E. H., and Rebeck, G. W. (2013). APOE genotype affects the pre-synaptic compartment of glutamatergic nerve terminals. J. Neurochem. 124, 4-14. doi: 10.1111/j.1471-4159.2012. 07908.x

Dumanis, S. B., Tesoriero, J. A., Babus, L. W., Nguyen, M. T., Trotter, J. H., Ladu, M. J., et al. (2009). ApoE4 decreases spine density and dendritic 
complexity in cortical neurons in vivo. J. Neurosci. 29, 15317-15322. doi: 10. 1523/JNEUROSCI.4026-09.2009

Grabrucker, A. M., Schmeisser, M. J., Udvardi, P. T., Arons, M., Schoen, M., Woodling, N. S., et al. (2011). Amyloid beta protein-induced zinc seuqestration leads to synaptic loss via dysregulation of the ProSAP2/Shank3 scaffold. Mol. Neurodegener. 6:65. doi: 10.1186/1750-1326-6-65

Graybeal, J. J., Bozzelli, P. L., Graybeal, L. L., Groeber, C. M., McKnight, P. E., Cox, D. N., et al. (2014). Human ApoE $\varepsilon 4$ alters circadian rhythm activity, IL-1 $\beta$, and GFAP in CRND8 mice. J. Alzheimers Dis. doi: 10.3233/JAD-132009. [Epub ahead of print].

Greenough, M. A., Camakaris, J., and Bush, A. I. (2013). Metal dyshomeostasis and oxidative stress in Alzheimer's disease. Neurochem. Int. 62, 540-545. doi: 10. 1016/j.neuint.2012.08.014

Greenough, M. A., Volitakis, I., Li, Q., Laughton, K., Evin, G., Ho, M., et al. (2011). Presenilins promote the cellular uptake of copper and zinc and maintain $\mathrm{Cu}$-chapterone of sod1-dependent $\mathrm{Cu} / \mathrm{Zn}$ superoxide dismutase activity. J. Biol. Chem. 286, 9776-9786. doi: 10.1016/j.jalz.2011. 05.514

Gruart, A., López-Ramos, J. C., Muñoz, M. D., and Delgado-García, J. M. (2008). Aged wild-type and APP, PS1 and APP + PS1 mice present similar deficits in associative learning and synaptic plasticity independent of amyloid load. Neurobiol. Dis. 30, 439-450. doi: 10.1016/j.nbd.2008. 03.001

Harris, F. M., Brecht, W. J., Xu, Q., Mahley, R. W., and Huang, Y. (2004). Increased tau phosphorylation in Apolipoprotein E4 transgenic mice is associated with activation of extracellular signal-regulated kinase. J. Biol. Chem. 279, 4479544801. doi: 10.1074/jbc.m408127200

Harris, C. J., Voss, K., Murchison, C., Ralle, M., Frahler, K., Carter, R., et al. (2014). Oral zinc reduces amyloid burden in tg2576 mice. J. Alzheimers Dis. 41, 179-192. doi: 10.3233/JAD-131703

Harvey, R. J., Skelton-Robinson, M., and Rosor, M. N. (2003). The prevalence and causes of dementia in people under the age of 65 years. J. Neurol. Neurosurg. Psychiatry 74, 1206-1209. doi: 10.1136/jnnp.74.9.1206

Hesse, L., Beher, D., Masters, C. L., and Multhaup, G. (1994). The $\beta$ A4 amyloid precursor protein binding to copper. FEBS Lett. 349, 109-116. doi: 10.1016/00145793(94)00658-X

Hölscher, C. (1999). Stress impairs performance in spatial water maze learning tasks. Behav. Brain Res. 100, 225-235. doi: 10.1016/s0166-4328(98) 00134-x

Huang, Y. (2006). Apolipoprotein E and Alzheimer's disease. Neurology 66(Suppl. 1), S79-S85. doi: 10.1212/01.wnl.0000192102.41141.9e

Huang, X., Atwood, C. S., Hartshorn, M. A., Multhaup, G., Goldstein, L. E., Scarpa, R. C., et al. (1999). The $\mathrm{A} \beta$ peptide of Alzheimer's disease directly produces hydrogen peroxide through metal ion reduction. Biochemistry 38, 7609-7616. doi: 10.1021/bi990438f

Huang, Y., and Mucke, L. (2012). Alzheimer mechanisms and therapeutic strategies. Cell 148, 1204-1222. doi: 10.1016/j.cell.2012.02.040

Klevay, L. M. (2008). Alzheimer's disease as copper deficiency. Med. Hypotheses 70, 802-807. doi: 10.1016/j.mehy.2007.04.051

Lee, J. Y., Cho, E., Kim, T. Y., Kim, D. K., Palmiter, R. D., Volitakis, I., et al. (2010). Apolipoprotein $\mathrm{E}$ ablation decreases synaptic vesicular zinc in the brain. Biometals 23, 1085-1095. doi: 10.1007/s10534-010-9354-9

Lee, J. Y., Cho, E., Seo, J. W., Hwang, J. J., and Koh, J. Y. (2012). Alteration of the cerebral zinc pool in a mouse model of Alzheimer's disease. J. Neuropathol. Exp. Neurol. 71, 211-222. doi: 10.1097/NEN.0b013e3182417387

Lee, J. Y., Cole, T. B., Palmiter, R. D., Suh, S. W., and Koh, J. Y. (2002). Contribution by synaptic zinc to the gender-disparate plaque formation in human Swedish mutant APP transgenic mice. Proc. Natl. Acad. Sci. U S A 99, 7705-7710. doi: 10. 1073/pnas.092034699

Linkous, D. H., Adlard, P. A., Wanschura, P. B., Conko, K. M., and Flinn, J. M. (2009). The effects of enhanced zinc on spatial memory and plaque formation in transgenic mice. J. Alzheimers Dis. 18, 565-579. doi: 10.3233/JAD-2009-1162

Linkous, D. H., Flinn, J. M., Koh, J. Y., Lanzirotti, A., Bertsch, P. M., Jones, B. F., et al. (2008). Evidence that that ZnT3 protein controls the total amount of elemental zinc in synaptic vesicles. J. Histochem. Cytochem. 56, 3-6. doi: 10. 1369/jhc.6a7035.2007

Lovell, M. A., Robertson, J. D., Teesdale, W. J., Campbell, J. L., and Markesbery, W. R. (1998). Copper, iron and zinc in Alzheimer's disease senile plaques. J. Neurol. Sci. 158, 47-52. doi: 10.1016/s0022-510x(98)00092-6
Mahley, R. W., Weisgraber, K. H., and Huang, Y. (2006). Apolipoprotein E4: a causative factor and therapeutic target in neuropathology, including Alzheimer's disease. Proc. Natl. Acad. Sci. U S A 103, 5644-5651. doi: 10.1073/pnas. 0600549103

Maynard, C. J., Bush, A. I., Masters, C. L., Cappai, R., and Li, Q.-X. (2005). Metals and amyloid $\beta$ in Alzheimer's disease. Int. J. Exp. Pathol. 86, 147-159. doi: 10. 1111/j.0959-9673.2005.00434.x

Milne, D. B., Davis, C. D., and Nielsen, F. H. (2001). Low dietary zinc alters indices of copper function and status in postmenopausal women. Nutrition 17, 701708. doi: 10.1016/s0899-9007(01)00560-3

Moreau, P., Bott, J., Zerbinatti, C., Renger, J. J., Kelche, C., Cassel, J., et al. (2013). Apoe4 confers better spatial memory than apoE3 in young adult hApp-Yac/apoE-Tr mice. Behav. Brain Res. 243, 1-5. doi: 10.1016/j.bbr.2012. 12.043

O'Leary, T. P., and Brown, R. E. (2013). Optimization of apparatus design and behavioral measures for the assessment of visuo-spatial learning and memory of mice on the Barnes maze. Learn. Mem. 20, 85-96. doi: 10.1101/lm.028076. 112

Palmiter, R. D., Cole, T. B., Quaife, C. J., and Findley, S. D. (1996). ZnT-3, a putative transporter of zinc into synaptic vesicles. Proc. Natl. Acad. Sci. U S A 93, 14934 14939. doi: 10.1073/pnas.93.25.14934

Pan, E., Zhang, X., Huang, Z., Krezel, A., Zhao, M., Tinberg, C. E., et al. (2011). Vesicular zinc promotes presynaptic and inhibits postsynaptic long-term potentiation of mossy fiber-CA3 synapse. Neuron 71, 1116-1126. doi: 10.1016/j. neuron.2011.07.019

Phinney, A. L., Drisaldi, B., Schmidt, S. D., Lugowski, S., Coronado, V., Liang, Y., et al. (2003). In vivo reduction of amyloid-beta by a mutant copper transporter. Proc. Natl. Acad. Sci. U S A 100, 14193-14198. doi: 10.1073/pnas. 2332851100

Railey, A. M., Groeber, C. M., and Flinn, J. M. (2011). The effect of metals on spatial memory in a transgenic mouse model of Alzheimer's disease. J. Alzheimers Dis. 23, 375-381. doi: 10.3233/JAD-2011-101452

Railey, A. M., Micheli, T. L., Wanschura, P. B., and Flinn, J. M. (2010). Alterations in fear response and spatial memory in pre- and post- natal zinc supplemented rats: remediation by copper. Physiol. Behav. 100, 95-100. doi: 10.1016/j.physbeh. 2010.01.040

Rebeck, G. W., Kindy, M., and LaDu, M. J. (2002). Apolipoprotein E and Alzheimer's disease: the protective effects of ApoE2 and E3. J. Alzheimers Dis. $4,145-154$.

Saunders, A. M., Strittmatter, W. J., Schmechel, D., Hyslop, P. H., Pericak-Vance, M. A., Joo, S. H., et al. (1993). Associate of apolipoprotein E allele epsilon-4 with late-onset familial and sporadic Alzheimer's disease. Neurology 43, 1467-1472. doi: $10.1212 /$ wnl.43.8.1467

Schmechel, D. E., Saunders, A. M., Strittmatter, W. J., Crain, B. J., Hulette, C. M., Joo, S. H., et al. (1993). Increased amyloid $\beta$-peptide deposition in cerebral cortex as a consequence of apolipoprotein E genotype in late-onset Alzheimer's disease. Proc. Natl. Acad. Sci. U S A 90, 9649-9653. doi: 10.1073/pnas.90.20. 9649

Sensi, S. L., Rapposelli, I. G., Frazzini, V., and Mascetra, N. (2008). Altered oxidantmediated intraneuronal zinc mobilization in a triple transgenic mouse model of Alzheimer's disease. Exp. Gerontol. 43, 488-492. doi: 10.1016/j.exger.2007. 10.018

Southon, A., Greenough, M. A., Ganio, G., Bush, A. I., Burke, R., and Camakaris, J. (2013). Presenilin promotes dietary copper uptake. PLoS One 8:e62811. doi: 10. 1371/journal.pone.0062811

Stoltenberg, M., Bush, A. I., Bach, G., Smidt, K., Larsen, A., Rungby, J., et al. (2007). Amyloid plaques arise from zinc-enriched cortical layers in APP/PS1 transgenic mice and are paradoxically enlarged with dietary zinc deficiency. Neuroscience 5, 357-369. doi: 10.1016/j.neuroscience.2007. 09.025

Tai, L. M., Bilousova, T., Jungbauer, L., Roeske, S. K., Youmans, K. L., Yu, C., et al. (2013). Levels of soluble apolipoprotein E/amyloid- $\beta$ (A $\beta$ ) complex are reduced and oligomeric $\mathrm{A} \beta$ increased with APOE4 and Alzheimer disease in a transgenic mouse model and human samples. J. Biol. Chem. 288, 5914-5926. doi: 10.1074/jbc.M112.442103

Wang, C. Y., Wang, T., Zheng, W., Zhao, B. L., Danscher, G., Chen, Y. H., et al. (2010). Zinc overload enhances APP cleavage and $A \beta$ deposition in the Alzheimer mouse brain. PLoS One 5:e15349. doi: 10.1371/journal.pone.00 15349 
Weisgraber, K. H., and Mahley, R. W. (1996). Human apolipoprotein E: the Alzheimer's disease connection. FASEB J. 10, 1485-1494.

Youmans, K. L., Tai, L. M., Nwabuisi-Heath, E., Jungbauer, L., Kanekiyo, T., Gan, M., et al. (2012). APOE4-specific changes in $\mathrm{A} \beta \mathrm{x}$ accumulation in a new transgenic mouse model of Alzheimer disease. J. Biol. Chem. 287, 41774-41786. doi: $10.1074 /$ jbc.M112.407957

Zannis, V. I., Just, P. W., and Breslow, J. L. (1981). Human apolipoprotein E isoprotein subclasses are genetically determined. Am. J. Hum. Genet. 33, $11-24$.

Conflict of Interest Statement: The authors declare that the research was conducted in the absence of any commercial or financial relationships that could be construed as a potential conflict of interest.
Received: 09 December 2013; accepted: 01 July 2014; published online: 22 October 2014.

Citation: Flinn JM, Bozzelli PL, Adlard PA and Railey AM (2014) Spatial memory deficits in a mouse model of late-onset Alzheimer's disease are caused by zinc supplementation and correlate with amyloid-beta levels. Front. Aging Neurosci. 6:174. doi: 10.3389/fnagi.2014.00174

This article was submitted to the journal Frontiers in Aging Neuroscience.

Copyright () 2014 Flinn, Bozzelli, Adlard and Railey. This is an open-access article distributed under the terms of the Creative Commons Attribution License (CC BY). The use, distribution or reproduction in other forums is permitted, provided the original author(s) or licensor are credited and that the original publication in this journal is cited, in accordance with accepted academic practice. No use, distribution or reproduction is permitted which does not comply with these terms. 